Revista Destaques Acadêmicos, Lajeado, v. 12, n. 4, 2020. ISSN 2176-3070

DOI: http://dx.doi.org/10.22410/issn.2176-3070.v12i4a2020.2597

http://www.univates.br/revistas

\title{
COMPARATIVO DE PESO DOS PÓRTICOS DE UM GALPÃO CONSIDERANDO SISTEMA EM TRELIÇAS E EM PERFIS DE ALMA CHEIA
}

\author{
Alysson Bianchini ${ }^{1}$, Rebeca Jéssica Schmitz ${ }^{2}$
}

Resumo. Galpões são edificações preferencialmente térreas utilizadas para os mais diversos fins, sendo sua estrutura composta por pórticos paralelos usualmente em concreto armado pré-fabricado ou aço. Em se tratando de galpões em aço tem-se duas tipologias bastante comuns: treliças e perfis de alma cheia (perfis I). Entende-se que para a escolha da estrutura devem ser considerados diversos fatores, sendo um deles o custo, que para estruturas metálicas, muitas vezes, está atrelado ao peso da estrutura (peso de aço) e ao número e complexidade das ligações. Dentro deste contexto, o presente trabalho teve como objetivo comparar o peso de aço necessário para o pórtico principal de um galpão hipotético considerando dois tipos de estrutura: treliças e perfis de alma cheia. Para essa análise foram desenvolvidos os dois projetos, sendo assim, inicialmente foram definidas as dimensões do galpão, o aço adotado (ASTM 572 grau 50) e os perfis utilizados. Para o pórtico em perfis de alma cheia, optou-se por perfis laminados $W$ nas vigas e perfis $W$ do tipo $H$ nos pilares. Já para o pórtico formado por treliças, optou-se pelo uso de perfis laminados U, sendo adotada treliça Pratt nas vigas e, nos pilares, do tipo Warren. Em seguida, foram estimados os carregamentos permanentes, variável de sobrecarga e de vento, para este último utilizou-se o software VisualVentos, e, após, foram combinados considerando o Estado Limite Último (ELU) normal. As duas estruturas foram modeladas no Ftool e com isso, verificados os esforços, a partir dos quais definiu-se os perfis necessários seguindo as diretrizes de dimensionamento da NBR 8800 (ABNT, 2008). Ao final, tem-se que o pórtico em treliças tem peso de $0,72 \mathrm{kN} / \mathrm{m}$ e o pórtico em perfis de alma cheia, $1,29 \mathrm{kN} / \mathrm{m}$. Se avaliado todas as cargas permanentes que engloba peso de elementos não estruturais, tem-se $2,22 \mathrm{kN} / \mathrm{m}$ sobre o pórtico em treliças e $2,79 \mathrm{kN} / \mathrm{m}$ para o pórtico em perfis de alma cheia, o que representa uma diferença de $25,7 \%$. Por fim, para o galpão avaliado entende-se que no quesito peso, o pórtico em treliça é mais vantajoso. Entretanto vale ressaltar que por essa diferença não ser tão significativa e considerando que a montagem de treliça é mais trabalhosa,

1 Engenheiro Civil graduado pela Univates. E-mail: alysson@universo.univates.br

2 Professora da Universidade do Vale do Taquari - Univates, Lajeado/RS. Engenheira Civil. Mestre em Estruturas. E-mail- rschmitz1@univates.br 
possivelmente a opção por pórtico em perfis de alma cheia seja mais vantajosa para situação analisada.

Palavras-chave: Galpões. Estrutura Metálica. Pórtico Treliçado. Pórtico em Perfis de Alma Cheia.

\section{INTRODUÇÃO}

Atualmente tem-se o aumento na demanda por galpões destinados aos mais diversos usos: armazenamento, indústria, quadras de esportes, entre outros. Percebe-se que os materiais mais empregados são o concreto armado pré-fabricado e o aço. Dentro disso, Chaves (2007) ressalta que o projeto estrutural engloba vários processos como, por exemplo: definir o sistema estrutural, escolher os materiais, analisar a estrutura, entre outros. Entende-se que em se tratando de galpões, o projeto em estrutura metálica dispõe de várias possibilidades para a concepção estrutural, sendo necessário definir a solução mais adequada. No passado, isso só era possível com uma boa experiência profissional, mas com a evolução da informática, hoje é possível obter vários modelos estruturais antes de definir a estrutura a ser utilizada, destaca o referido autor.

Dentro deste contexto, o objetivo geral deste trabalho é comparar o peso do pórtico principal de um galpão hipotético considerando duas concepções estruturais: treliças e perfis de alma cheia. Entende-se que em estruturas metálicas, o peso da estrutura está diretamente relacionado ao custo da mesma.

Segundo Nogueira (2009), por causa da competitividade no mercado, o custo de uma edificação é um parâmetro muito importante, que deve ser levado em conta, particularmente na área de estruturas metálicas. Os projetos devem se basear principalmente na segurança, durabilidade e economia, pois estas características são a base para conseguir competitividade em um projeto. Para Bareiro (2015), a cada dia é exigido maior redução de material e mais velocidade na execução de galpões.

\section{GALPÕES}

Os galpões são obras geralmente constituídas de aço ou concreto préfabricado em um único pavimento, composto de sistemas estruturais de pórticos espaçados, com a cobertura superior apoiada em terças e vigas, ou tesouras e treliças. Essas edificações normalmente abrangem grandes áreas coberturas, projetadas para uso comercial, industrial, agrícola ou esportivo (PRAVIA; DREHMER; MESACASA JÚNIOR, 2010).

\subsection{Pórticos de perfis I}

Para as vigas de alma cheia que compõem pórticos de galpões são utilizados perfis laminados ou soldados de inércia constante ao longo do vão, 
apesar de ser possível a diminuição do peso da viga utilizando perfis de inércia variável. Antigamente, no Brasil, o uso de vigas de alma cheia era limitado, devido à escassez de perfis de dimensões pequenas e com relação inércia/peso aceitável. Com a atual disponibilidade de perfis de dimensões pequenas, a limitação foi deixada no passado (CHAVES, 2007).

As propriedades geométricas dos perfis podem ser encontradas em normas, ou então em manuais de fabricantes. O pré-dimensionamento da altura da viga de pórtico de galpões sem pontes rolantes em perfis de alma cheia é dada pela Equação 1 (PRAVIA; DREHMER; MESACASA JÚNIOR, 2010).

$$
\frac{d}{L}=\frac{1}{50} a \frac{1}{70}
$$

Sendo:

$d$ : altura do perfil;

$L$ : vão da viga.

Existe uma variedade de perfis, soldados ou laminados, que podem ser adotados para compor o fuste de uma coluna de alma cheia. O perfil mais racional sob o ponto de vista de trabalho é o perfil tubular, mas ele é pouco usado em galpões por causa do custo e da dificuldade em fazer as ligações. As seções I ou H, soldadas ou laminadas, são as mais básicas, sendo que o perfil I laminado não é tão utilizado devido ao baixo raio de giração no sentido da menor inércia, sendo uma opção em galpões pequenos sem pontes rolantes. Já o perfil H laminado é ideal para grandes edificações por ter raios de giração muito próximos nos dois sentidos. Para colunas com altura constante em perfis de alma cheia é recomendada a relação conforme a Equação 2 (BELLEI, 2010).

$$
\frac{d}{H}=\frac{1}{20} a \frac{1}{30}
$$

Sendo:

$d$ : altura do perfil;

$H$ : altura do pilar.

\subsection{Pórticos treliçados}

Segundo Pfeil e Pfeil (2016), as hastes das treliças sofrem principalmente com a tração ou compressão simples. O modelo teórico de análise de treliça tem os nós rotulados, mas quando elas são construídas, verifica-se que possuem nós rígidos, o que introduz momentos fletores nas hastes. Entretanto por terem seção transversal muito reduzida em relação ao seu comprimento, as tensões de flexão são pequenas, e, muitas vezes, são ignoradas.

Segundo Bellei (2010), em edifícios de grandes vãos é mais indicada a utilização de sistemas de vigas treliçadas com pouca inclinação. De acordo com 
Fakury, Silva e Caldas (2016), os perfis U são utilizados em pilares submetidos a pouca carga, barras de tapamento, terças e elementos de treliças, que é o caso analisado no presente trabalho. As barras em perfis $U$, recorrentes em treliças, são fabricadas no Brasil por várias empresas, sendo que a altura do perfil pode variar de 76,2 milímetros ( $\left.3^{\prime \prime}\right)$ até 381 milímetros $\left(15^{\prime \prime}\right)$, seguindo a padronização norte-americana (BELLEI, 2010).

Para o pré-dimensionamento das vigas treliçadas, Melo (2013) indica as Equações (3) e (4):

$$
\begin{aligned}
& h=0,26 \cdot L^{0,57} \\
& m=0,37 \cdot L^{0,42}
\end{aligned}
$$

Sendo:

$h$ : altura das barras montantes;

$L$ : vão da viga;

$m$ : espaçamento entre os nós.

Bellei (2010) indica que o fuste de uma coluna treliçada é formado de um ou mais perfis laminados, ligados por chapas ou cantoneiras localizadas nos planos das mesas. As colunas treliçadas tem resistência equivalente às colunas em alma cheia. Geralmente o fuste é formado por um par de perfis U laminados e com as abas viradas para dentro, pois não é vantajoso quando as abas estão viradas para fora, pois há maior gasto de material. $\mathrm{O}$ autor apresenta alguns exemplos de interligação de perfis para uso em pilares, sendo os três primeiros sistemas treliçados: Warren (FIGURA 1.a), Pratt (FIGURA 1.b), diagonais cruzadas (FIGURA 1.c), uso de talas para união (FIGURA 1.d), perfis de chapas vazadas (FIGURA 1.e).

Figura 1 - Interligação de perfis para uso em pilares

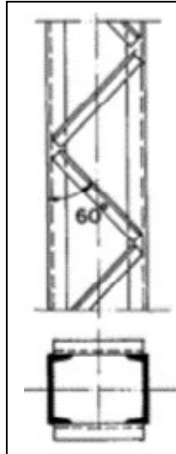

(a)

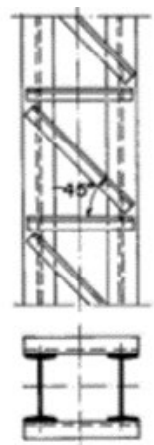

(b)

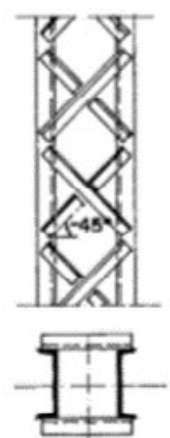

(c)
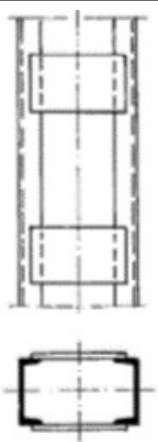

(d)

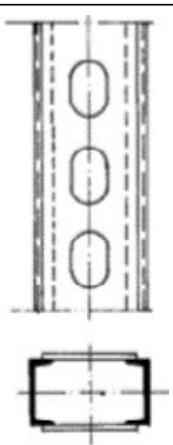

(e)

Fonte: Bellei (2010, p. 209). 
Para o dimensionamento dos pilares treliçados, recomenda-se a relação dada pela Equação 5 (BELLEI, 2010).

$$
\frac{l}{H}=\frac{1}{15} a \frac{1}{18}
$$

Sendo:

$l$ : largura do pilar;

$H$ : altura do pilar.

\section{PROCEDIMENTOS METODOLÓGICOS}

\subsection{Determinação das dimensões do galpão}

Através da pesquisa foram definidas as dimensões do galpão hipotético que teve o pórtico principal dimensionado com dois sistemas estruturais diferentes, sendo as dimensões iguais para ambos, para que seja definido o sistema que utiliza a menor quantidade de aço. As dimensões adotadas são as seguintes (FIGURA 2):
a) vão livre: 20,00 metros;
b) espaçamento entre pórticos transversais: 6,00 metros;
c) altura das colunas: 9,00 metros;
d) inclinação da cobertura: $10 \%$;
e) comprimento total: 54,00 metros.

As escolhas das dimensões foram feitas com base em Bellei (2010) e Pfeil e Pfeil (2016), pois ambos os autores apresentam dimensões usuais para galpões, sendo que a delimitação do vão livre considerou o uso de perfis sem necessidade de emenda. Em relação a inclinação de cobertura, determinou-se 10\% de inclinação, conforme Pravia, Drehmer e Mesacasa Júnior (2010). 
Figura 2 - Dimensões do galpão

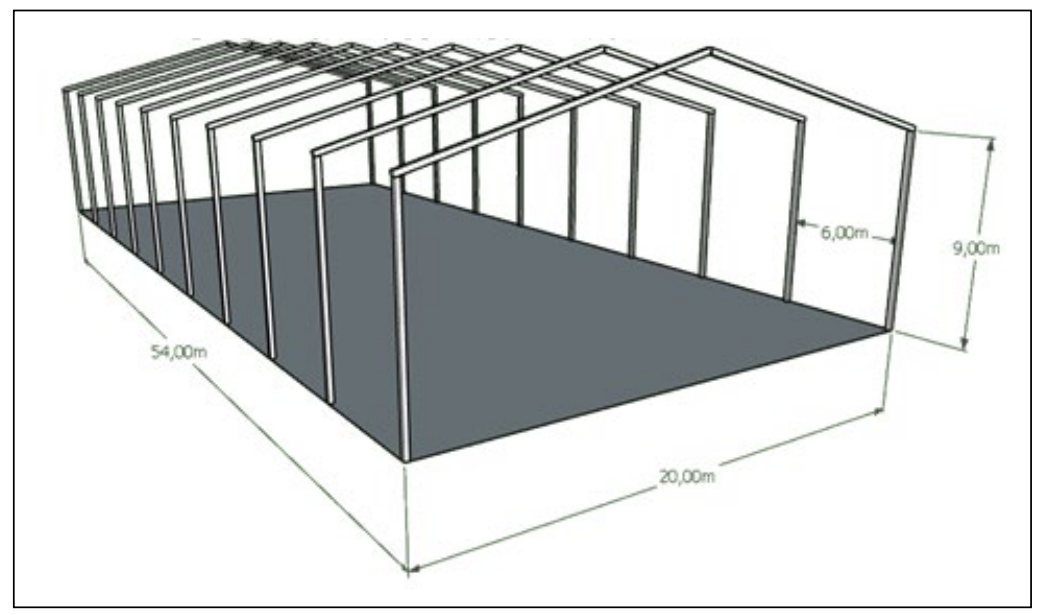

Fonte: autor.

\subsection{Pré-dimensionamento}

Para os dois galpões foram consideradas ligações rotuladas entre pilares e fundações, considerando que se enquadram em pequeno-médio porte seguiuse a recomendação de Bellei (2010). Já em relação, a ligação entre pilares e vigas, adotou-se ligação rígida a fim de garantir a estabilidade a estrutura. $\mathrm{O}$ aço adotado para todos perfis foi o ASTM A 572 Grau 50, que é o aço padronizado para perfis da série $W$, sendo adotado o mesmo para perfis $U$, a fim de permitir a comparação entre as duas estruturas. A seguir são apresentados os parâmetros específicos de cada sistema, incialmente o pórtico com perfis I e em seguida o pórtico treliçado.

Considerando que o pórtico em perfis de alma cheia será constituído por perfis I laminados da série W, em se tratando dos pilares, seguindo a Equação 2 de pré-dimensionamento, foi obtido o valor de altura do perfil entre 300 e $450 \mathrm{~mm}$, com isso selecionou-se o W $360 \times 91,0(\mathrm{H})$ que tem $353 \mathrm{~mm}$ de altura de acordo com Tabela de Bitolas da Gerdau (2018). Já para as vigas, a partir da Equação 1 tem-se a altura do perfil estimada em 285,7 a $400 \mathrm{~mm}$, sendo assim escolhido o W 310 × 21,0 com altura de $303 \mathrm{~mm}$ segundo a Tabela de Bitolas da Gerdau (2018).

Avaliando o pórtico treliçado, inicialmente foram definidas as dimensões das treliças (FIGURA 3) e num segundo momento foi adotado um parâmetro como referência para o peso dos perfis. Os pilares serão do tipo Warren (FIGURA 1.a) sendo a largura do pilar (distância dos banzos da treliça) definida em 600 mm devido aos valores obtidos pela aplicação da Equação 5, já a distância entre nós foi definida considerando que a inclinação das diagonais 
seria $45^{\circ}$. Para as vigas adotou-se a treliça tipo Pratt com os banzos paralelos (FIGURA 1.b), sendo que através das Equações 3 e 4 definiu-se que a altura da viga treliçada seria de 1,50 m e o espaçamento entre nós ao longo do vão igual a 1,30 m. A orientação das diagonais levou em consideração quando a cobertura estiver sob sucção, gerada pelo vento, as diagonais estarão tracionadas.

Figura 3 - Pórtico treliçado

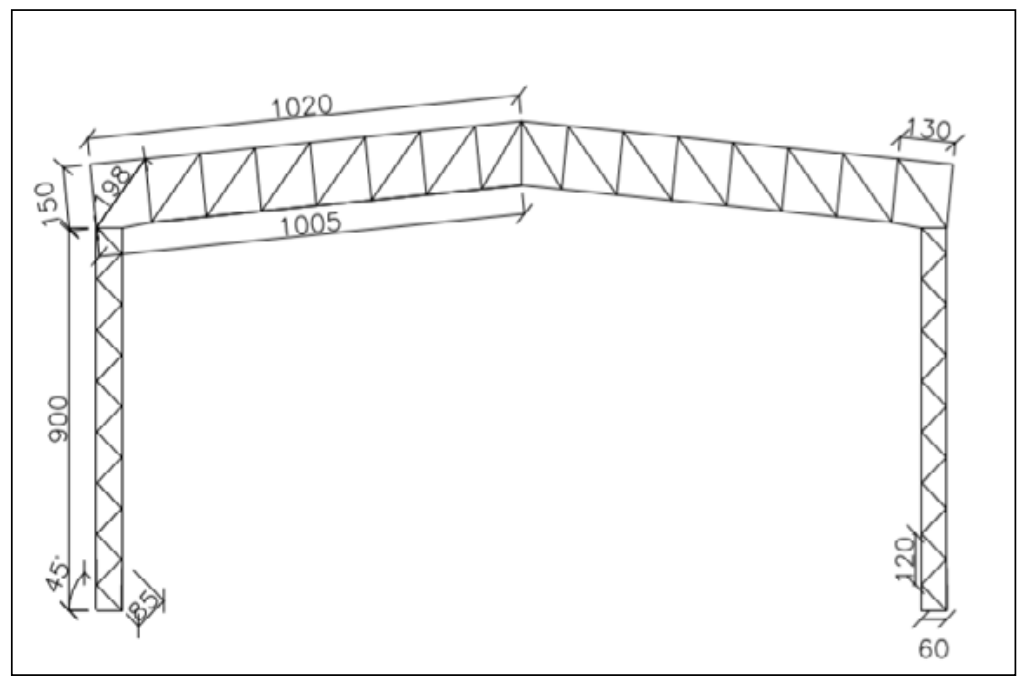

Fonte: autor.

Para todas as barras das treliças, tanto da viga, como dos pilares, serão utilizados perfis $U$, sendo adotado um parâmetro para a massa dos perfis ao invés da escolha dos perfis devido à falta de recomendações e também pela necessidade de se ter dados de peso para definição das cargas atuantes. Sendo assim, adotou-se $10 \mathrm{~kg} / \mathrm{m}$ para os perfis dos banzos e $6 \mathrm{~kg} / \mathrm{m}$ para os perfis das barras montantes e diagonais.

\subsection{Determinação das cargas atuantes}

As cargas atuantes no galpão foram determinadas com embasamento na NBR 8800 (ABNT, 2008), sendo consideradas cargas permanentes, variável de sobrecarga e devidas ao vento.

\subsubsection{Cargas permanentes}

As cargas permanentes são relativas ao peso do pórtico principal, de outros elementos estruturais (contraventamentos, terças, tirantes) e elementos não estruturais como as telhas. Entende-se que a única carga necessariamente diferente para os dois sistemas estruturais é o peso do pórtico principal, sendo essas definidas em um segundo momento. Primeiramente, foram avaliadas 
as cargas permanentes comuns nos dois sistemas, para as quais seguiu-se as recomendações de Pravia, Drehmer e Mesacasa Júnior (2010):

a) contraventamentos: $0,05 \mathrm{kN} / \mathrm{m}^{2}$;

b) telhas: $0,10 \mathrm{kN} / \mathrm{m}^{2}$;

c) terças e tirantes: $0,10 \mathrm{kN} / \mathrm{m}^{2}$.

Considerando o espaçamento de 6 metros entre pórticos tem-se que essa parcela da carga permanente representa $1,5 \mathrm{kN} / \mathrm{m}$. Além disso, deve ser considerada a carga de peso do pórtico, que para o caso em perfis I, considerouse a massa dos perfis escolhidos: $91 \mathrm{~kg} / \mathrm{m}$ para o pilar e $21 \mathrm{~kg} / \mathrm{m}$ para a viga, de forma aproximada considerou-se como carga distribuída ao longo de todo vão da viga, o que totalizou $1,01 \mathrm{kN} / \mathrm{m}$. Desta forma, a cargas permanente para o galpão em pórtico composto por perfil I ficou igual a $2,51 \mathrm{kN} / \mathrm{m}$ como podese observar na Tabela 1.

Tabela 1 - Cargas permanentes pórtico com perfis de alma cheia

\begin{tabular}{c|c}
\hline Descrição da carga & Valor $(\mathrm{kN} / \mathrm{m})$ \\
\hline Viga alma cheia & 0,21 \\
\hline Pilar alma cheia & 0,80 \\
\hline Contraventamento & 0,30 \\
\hline Telhas & 0,60 \\
\hline Terças e tirantes & 0,60 \\
\hline TOTAL & 2,51 \\
\hline
\end{tabular}

Fonte: autor.

Em se tratando do pórtico treliçado, considerou-se que a massa dos banzos seria $10 \mathrm{~kg} / \mathrm{m}$ e, das diagonais e montantes, $6 \mathrm{~kg} / \mathrm{m}$. A partir disso, contabilizou-se os comprimentos dos elementos e obteve-se a massa total do pórtico, este valor foi dividido pelo vão da viga, pois da mesma forma que feito para o pórtico em perfis I, considerou-se que o peso estaria distribuído uniformemente ao longo deste vão. Desta forma, conforme visto na Tabela 2, a carga referente ao pórtico fica dada pela soma das duas primeiras parcelas, totalizando $0,53 \mathrm{kN} / \mathrm{m}$ somando as demais parcelas tem-se que as cargas permanentes representam $2,03 \mathrm{kN} / \mathrm{m}$. 
Tabela 2 - Cargas permanentes perfis treliçados

\begin{tabular}{c|c}
\hline Descrição da carga & Valor $(\mathrm{kN} / \mathrm{m})$ \\
\hline Diagonais e montantes & 0,16 \\
\hline Banzos & 0,37 \\
\hline Contraventamento & 0,30 \\
\hline Telhas & 0,60 \\
\hline Terças e tirantes & 0,60 \\
\hline TOTAL & 2,03 \\
\hline
\end{tabular}

Fonte: autor.

\subsubsection{Carga variável de sobrecarga}

A carga variável de sobrecarga é igual para ambos pórticos, sendo que a NBR 8800 (ABNT, 2008) indica que, quando não há uma especificação mais detalhada, deve-se considerar carga mínima de $0,25 \mathrm{kN} / \mathrm{m}^{2}$ em projeção horizontal. A partir deste valor e considerando o espaçamento entre pórticos igual a 6 metros, tem-se que a carga sobre cada pórtico será igual a 1,50 kN/m.

\subsubsection{Cargas devidas ao vento}

O cálculo das cargas devidas ao vento foi feito com o software Visual Ventos que está de acordo com as recomendações da NBR 6123 (ABNT, 1988). Os critérios utilizados para o cálculo foram:

a) velocidade básica do vento v0: $45 \mathrm{~m} / \mathrm{s}$, velocidade que atende boa parte do Brasil, segundo as isopletas da NBR 6123 (ABNT, 1988);

b) fator topográfico s1: 1,00 (terreno plano fracamente acidentado); classe C);

c) fator de rugosidade s2: 0,88 (categoria de terreno III e edificação de

d) fator estatístico s3: 0,95 (instalações industriais de baixa ocupação);

e) coeficiente de pressão interna: 0,2 e -0,3.

$\mathrm{Na}$ Figura 4 pode-se observar os quatro casos de carga que representam a ação do vento. Dentre eles verifica-se que o caso " $b$ " é semelhante ao caso "a" entretanto tem todos os valores de carga reduzidos, sendo assim, com certeza este caso não leva à condição mais crítica da estrutura e por isto será desprezado. 
Figura 4 - Casos de força de vento a) vento $0^{\circ}$ coeficiente de pressão interna $0,2 ; \mathrm{b})$ vento $0^{\circ}$ coeficiente de pressão interna $-0,3$; c) vento $90^{\circ}$ coeficiente de pressão interna 0,$2 ; d$ ) vento $90^{\circ}$ coeficiente de pressão interna $-0,3$

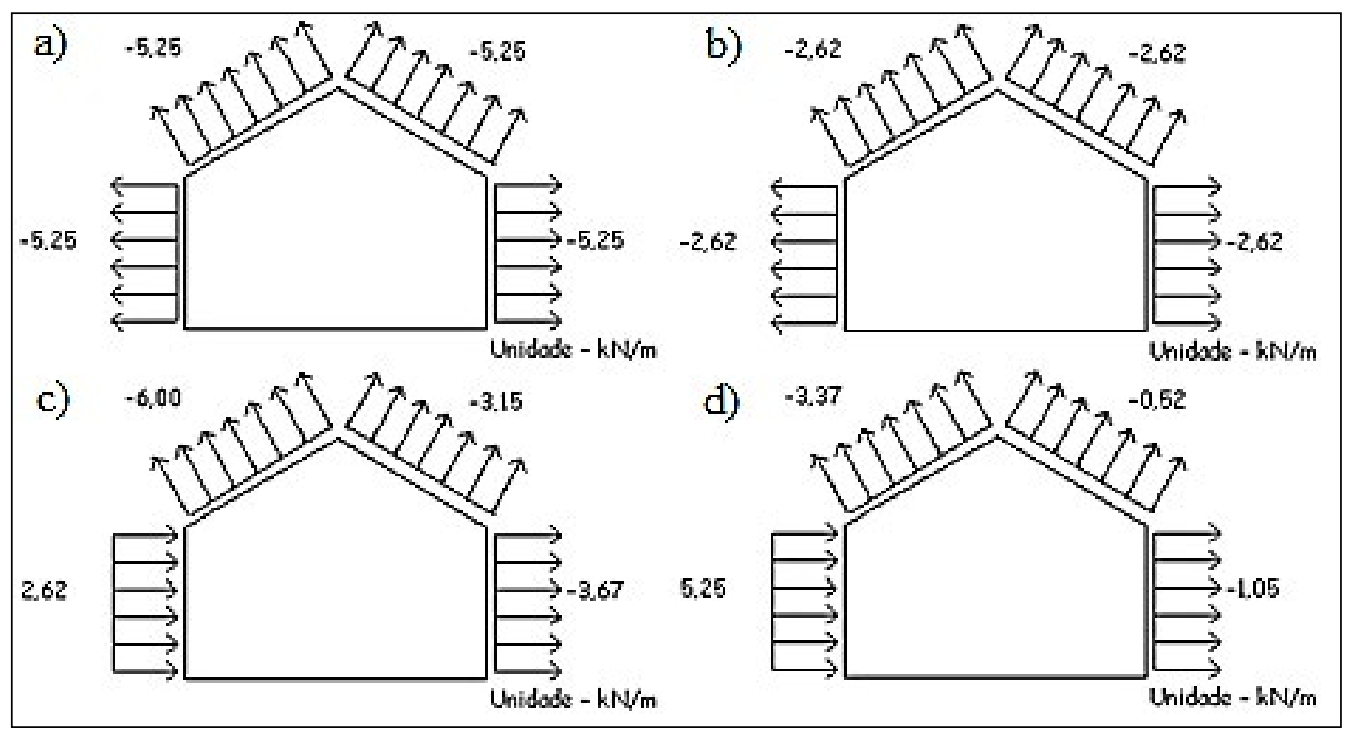

Fonte: autor.

\subsubsection{Combinações}

As combinações foram realizadas conforme o Estado Limite Último (ELU) para a condição normal de acordo com a NBR 8681 (ABNT, 2004). Um resumo das combinações com a identificação e os coeficientes considerados pode ser observado na Tabela 3. Já na Tabela 4 estão os resultados das cargas combinadas sendo indicada a combinação, a posição da carga o valor já com o sentido. A saber as cargas verticais negativas são para baixo e as horizontais negativas são para esquerda.

Tabela 3 - Combinações das cargas

\begin{tabular}{c|c|c|c|c}
\hline Combinação & $\begin{array}{c}\text { Carga } \\
\text { permanente }\end{array}$ & $\begin{array}{c}\text { Coeficiente de } \\
\text { ponderação da } \\
\text { carga permanente }\end{array}$ & Carga variável & $\begin{array}{c}\text { Coeficiente de } \\
\text { ponderação da } \\
\text { carga variável }\end{array}$ \\
\hline 1 & desfavorável & 1,25 & $\begin{array}{c}\text { sobrecarga na } \\
\text { cobertura }\end{array}$ & 1,50 \\
\hline 2 & favorável & 1,00 & vento $0^{\circ}$ (caso a) & 1,40 \\
\hline 3 & favorável & 1,00 & vento $90^{\circ}$ (caso c) & 1,40 \\
\hline 4 & favorável & 1,00 & vento $90^{\circ}$ (caso d) & 1,40 \\
\hline
\end{tabular}

Fonte: autor. 
Tabela 4 - Combinações das cargas

\begin{tabular}{|c|c|c|c|}
\hline Combinação & Posição da carga & Pórtico & Valor $(\mathrm{kN} / \mathrm{m})$ \\
\hline \multirow{2}{*}{1} & \multirow{2}{*}{ vertical sobre toda cobertura } & Alma Cheia & $-5,39$ \\
\hline & & Treliça & $-4,79$ \\
\hline \multirow{6}{*}{2} & \multirow{2}{*}{ vertical sobre toda cobertura } & Alma Cheia & 4,73 \\
\hline & & Treliça & 5,20 \\
\hline & horizontal sobre cobertura lado esquerdo & Ambos & $-1,28$ \\
\hline & horizontal sobre cobertura lado direito & Ambos & 1,28 \\
\hline & horizontal sobre pilar esquerdo & Ambos & $-7,35$ \\
\hline & horizontal sobre pilar direito & Ambos & 7,35 \\
\hline \multirow{8}{*}{3} & \multirow{2}{*}{ vertical sobre cobertura lado esquerdo } & Alma Cheia & 5,76 \\
\hline & & Treliça & 6,24 \\
\hline & \multirow{2}{*}{ vertical sobre cobertura lado direito } & Alma Cheia & 1,83 \\
\hline & & Treliça & 2,31 \\
\hline & horizontal sobre cobertura lado esquerdo & Ambos & $-1,46$ \\
\hline & horizontal sobre cobertura lado direito & Ambos & 0,77 \\
\hline & horizontal sobre pilar esquerdo & Ambos & 3,67 \\
\hline & horizontal sobre pilar direito & Ambos & 5,14 \\
\hline \multirow{8}{*}{4} & \multirow{2}{*}{ vertical sobre cobertura lado esquerdo } & Alma Cheia & 2,14 \\
\hline & & Treliça & 2,61 \\
\hline & \multirow{2}{*}{ vertical sobre cobertura lado direito } & Alma Cheia & $-1,79$ \\
\hline & & Treliça & $-1,32$ \\
\hline & horizontal sobre cobertura lado esquerdo & Ambos & $-0,82$ \\
\hline & horizontal sobre cobertura lado direito & Ambos & 0,13 \\
\hline & horizontal sobre pilar esquerdo & Ambos & 7,35 \\
\hline & horizontal sobre pilar direito & Ambos & 1,47 \\
\hline
\end{tabular}

Fonte: autor.

\subsection{Modelagem da estrutura}

A etapa seguinte foi de modelagem dos dois pórticos, cada um sob quatro combinações de carga. Para isso, utilizou-se o software Ftool, pois se trata de um programa com interface muito simples e de fácil utilização, onde o usuário cria e manipula com eficiência os modelos estruturais, com a possibilidade de interpretar o comportamento destas estruturas. Além disso, este programa é disponibilizado gratuitamente e atende aos requisitos para se fazer os modelos propostos no trabalho, modelagem de barras no plano.

Foram realizados dois modelos de pórtico: um de perfis de alma cheia com carregamento distribuído e outro, sistema treliçado, com carregamentos pontuais nos nós. Cada modelo recebeu as combinações do item 3.3.4. A critério de exemplo é apresentada nas Figuras 5 e 6 a combinação 2 aplicada nos dois pórticos. 
Figura 5 - Pórtico em perfis de alma cheia (combinação 2)

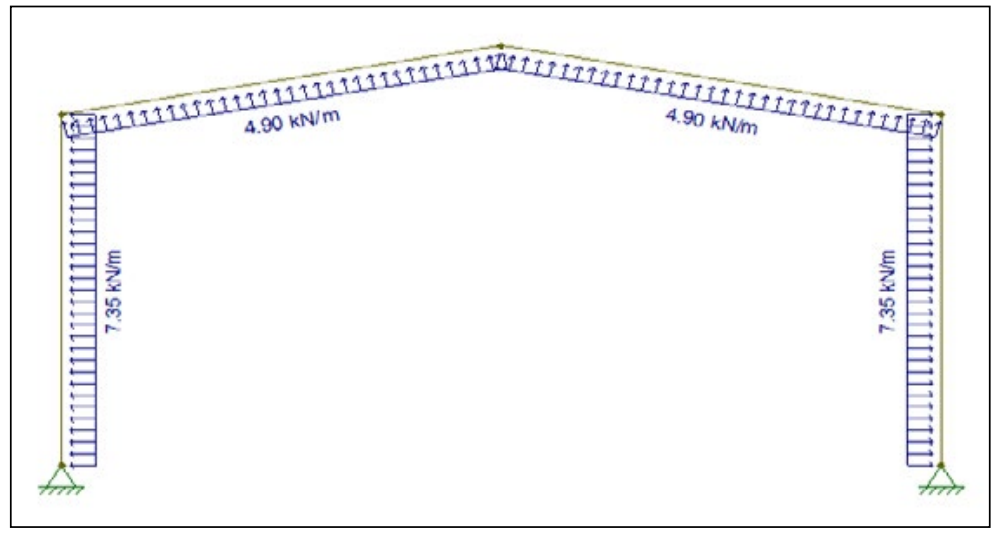

Fonte: autor.

Figura 6 - Pórtico treliçado (combinação 2)

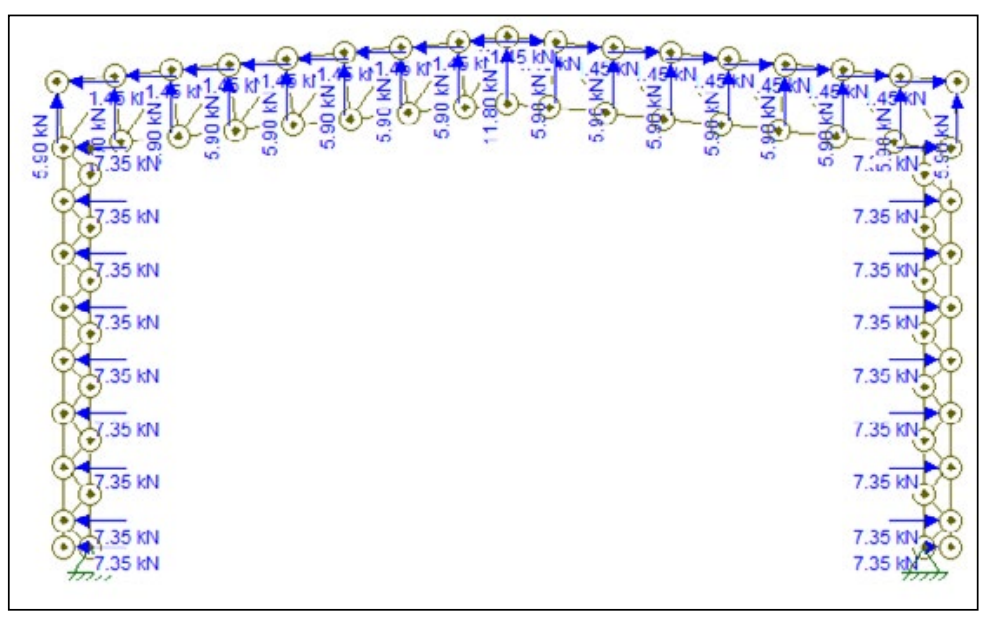

Fonte: autor.

\subsection{Dimensionamento dos elementos}

Para a estrutura em alma cheia foram verificados os esforços normais e cortantes e também os momentos fletores atuantes na estrutura. As verificações, conforme a NBR 8800 (ABNT, 2008) foram realizadas através da planilha para perfis laminados, disponibilizada pela Gerdau. Nas Tabelas 5 e 6 podem ser vistos os cálculos realizados para os pilares e vigas em perfis de alma cheia, respectivamente. A saber as combinações que não estão indicadas foram 
descartadas para análise do elemento em questão por não gerarem a condição de solicitação mais crítica.

\section{Tabela 5 - Verificações dos pilares em alma cheia (perfil W 250 X 89,0 H)}

\begin{tabular}{|c|c|c|c|c|c|c|c|c|}
\hline \multicolumn{3}{|c|}{ Combinação 1} & \multicolumn{3}{|c|}{ Combinação 3} & \multicolumn{3}{|c|}{ Combinação 4} \\
\hline \multicolumn{9}{|c|}{ Verificação da esbeltez do perfil } \\
\hline Limite & Obtido & $\%$ & Limite & Obtido & $\%$ & Limite & Obtido & $\%$ \\
\hline 200 & 161 & $80,50 \%$ & 300 & 161 & $53,67 \%$ & 300 & 161 & $53,67 \%$ \\
\hline 200 & 97 & $48,31 \%$ & 300 & 97 & $32,21 \%$ & 300 & 97 & $32,21 \%$ \\
\hline \multicolumn{3}{|c|}{ Resistência à compressão } & \multicolumn{3}{|c|}{ Resistência à tração } & \multicolumn{3}{|c|}{ Resistência à tração } \\
\hline $\operatorname{Nrd}(\mathrm{kN})$ & $\mathrm{Nsd}(\mathrm{kN})$ & $\%$ & $\operatorname{Nrd}(\mathrm{kN})$ & $\mathrm{Nsd}(\mathrm{kN})$ & $\%$ & $\operatorname{Nrd}(k N)$ & $\mathrm{Nsd}(\mathrm{kN})$ & $\%$ \\
\hline 709 & 54,70 & $7,72 \%$ & 3572 & 62,90 & $1,76 \%$ & 3572 & 26,20 & $0,73 \%$ \\
\hline \multicolumn{9}{|c|}{ Resistência à flexão } \\
\hline $\operatorname{Mrd}(\mathrm{kN} . \mathrm{cm})$ & $\begin{array}{c}\text { Msd(kN. } \\
\mathrm{cm})\end{array}$ & $\%$ & $\operatorname{Mrd}(\mathrm{kN} . \mathrm{cm})$ & $\begin{array}{c}\operatorname{Msd}(\mathrm{kN} . \\
\mathrm{cm})\end{array}$ & $\%$ & $\operatorname{Mrd}(\mathrm{kN} . \mathrm{cm})$ & $\begin{array}{c}\text { Msd(kN. } \\
\mathrm{cm})\end{array}$ & $\%$ \\
\hline 28027 & 16380 & $58,44 \%$ & 28027 & 25670 & $91,59 \%$ & 28027 & 17640 & $62,94 \%$ \\
\hline \multicolumn{9}{|c|}{ Resistência ao esforço cortante } \\
\hline $\operatorname{Vrd}(\mathrm{kN})$ & $\mathrm{Vsd}(\mathrm{kN})$ & $\%$ & $\operatorname{Vrd}(\mathrm{kN})$ & $\mathrm{Vsd}(\mathrm{kN})$ & $\%$ & $\operatorname{Vrd}(\mathrm{kN})$ & $\mathrm{Vsd}(\mathrm{kN})$ & $\%$ \\
\hline 524 & 18,20 & $3,48 \%$ & 524 & 45 & $8,60 \%$ & 524 & 50,90 & $9,72 \%$ \\
\hline \multicolumn{9}{|c|}{ Resistência aos esforços combinados } \\
\hline Nsd/Nrd & \multicolumn{2}{|c|}{0,077} & Nsd/Nrd & \multicolumn{2}{|c|}{0,018} & Nsd/Nrd & \multicolumn{2}{|c|}{0,007} \\
\hline Combinação & Limite & Cálculo & Combinação & Limite & Cálculo & Combinação & Limite & Cálculo \\
\hline $\mathrm{Ne} \mathrm{M}$ & $100 \%$ & $62,30 \%$ & $\mathrm{~N}$ e $\mathrm{M}$ & $100 \%$ & $92,47 \%$ & $\mathrm{Ne} \mathrm{M}$ & $100 \%$ & $63,31 \%$ \\
\hline
\end{tabular}

Fonte: autor.

Tabela 6 - Verificações das vigas em alma cheia (perfil W 460 X 52,0)

\begin{tabular}{|c|c|c|c|c|c|c|c|c|}
\hline \multicolumn{3}{|c|}{ Combinação 1} & \multicolumn{3}{|c|}{ Combinação 2} & \multicolumn{3}{|c|}{ Combinação 3} \\
\hline \multicolumn{9}{|c|}{ Verificação da esbeltez do perfil } \\
\hline Limite & Obtido & $\%$ & Limite & Obtido & $\%$ & Limite & Obtido & $\%$ \\
\hline 200 & 57 & $28,34 \%$ & 300 & 57 & $18,89 \%$ & 300 & 57 & $18,89 \%$ \\
\hline 200 & 84 & $42,07 \%$ & 300 & 84 & $28,05 \%$ & 300 & 84 & $28,05 \%$ \\
\hline \multicolumn{3}{|c|}{ Resistência à compressão } & \multicolumn{3}{|c|}{ Resistência à tração } & \multicolumn{3}{|c|}{ Resistência à tração } \\
\hline $\operatorname{Nrd}(\mathrm{kN})$ & $\mathrm{Nsd}(\mathrm{kN})$ & $\%$ & $\operatorname{Nrd}(\mathrm{kN})$ & Nsd(kN) & $\%$ & $\operatorname{Nrd}(\mathrm{kN})$ & $\mathrm{Nsd}(\mathrm{kN})$ & $\%$ \\
\hline 1162 & 27,40 & $2,36 \%$ & 2089 & 58,10 & $2,78 \%$ & 2089 & 27,20 & $1,30 \%$ \\
\hline \multicolumn{9}{|c|}{ Resistência à flexão } \\
\hline $\operatorname{Mrd}(\mathrm{kN} . \mathrm{cm})$ & $\begin{array}{c}\text { Msd(kN. } \\
\mathrm{cm})\end{array}$ & $\%$ & $\operatorname{Mrd}(\mathrm{kN} . \mathrm{cm})$ & $\begin{array}{c}\text { Msd(kN. } \\
\mathrm{cm})\end{array}$ & $\%$ & $\operatorname{Mrd}(\mathrm{kN} . \mathrm{cm})$ & $\begin{array}{c}\text { Msd(kN. } \\
\mathrm{cm})\end{array}$ & $\%$ \\
\hline 27458 & 16380 & $59,65 \%$ & 27458 & 11630 & $42,36 \%$ & 27458 & 25670 & $93,49 \%$ \\
\hline \multicolumn{9}{|c|}{ Resistência ao esforço cortante } \\
\hline $\operatorname{Vrd}(\mathrm{kN})$ & Vsd(kN) & $\%$ & $\operatorname{Vrd}(\mathrm{kN})$ & Vsd(kN) & $\%$ & $\operatorname{Vrd}(\mathrm{kN})$ & Vsd(kN) & $\%$ \\
\hline 644 & 50,70 & $7,88 \%$ & 644 & 39,30 & $6,11 \%$ & 644 & 59,90 & $9,31 \%$ \\
\hline \multicolumn{9}{|c|}{ Resistência aos esforços combinados } \\
\hline Nsd/Nrd & \multicolumn{2}{|c|}{0,024} & Nsd/Nrd & \multicolumn{2}{|c|}{0,028} & Nsd/Nrd & \multicolumn{2}{|c|}{0,013} \\
\hline Combinação & Limite & Cálculo & Combinação & Limite & Cálculo & Combinação & Limite & Cálculo \\
\hline Ne M & $100 \%$ & $60,83 \%$ & $\mathrm{NeM}$ & $100 \%$ & $43,75 \%$ & $\mathrm{NeM}$ & $100 \%$ & $94,14 \%$ \\
\hline
\end{tabular}

Fonte: autor. 
Os dados de solicitação foram gerados pelo software Ftool e os dados de resistência foram calculados através da planilha. A comparação destes dados gerou uma porcentagem, sendo que, quanto mais próximo de $100 \%$ mais otimizado está o dimensionamento e se estiver acima de $100 \%$ o perfil não irá atender à solicitação. Dessa forma, foi possível escolher o perfil que atendesse a todos os esforços solicitantes e também tivesse a relação mais otimizada entre resistência e solicitação.

No caso do pórtico treliçado avaliou-se a resistência de perfis U para esforços axiais de compressão e tração nas barras das treliças dos pilares e da viga. Essa verificação fez-se com o uso da planilha para perfis U, desenvolvida por Pravia (2008), que segue as indicações da NBR 8800 (ABNT, 2008). A planilha contribuiu para dar agilidade na escolha dos perfis, sendo estes otimizados e padronizados, considerando também a necessidade de encaixe das barras montantes e diagonais nos banzos. As Tabelas 7 e 8 apresentam um resumo dos esforços mais críticos que foram verificados para cada tipo de perfil, sendo que novamente a porcentagem é a relação entre solicitação e resistência.

Tabela 7 - Verificações das barras das treliças dos pilares

\begin{tabular}{c|c|c|c|c|c|c}
\hline Barra & \multicolumn{3}{|c|}{ Banzos $(5 \times 13,4)$} & \multicolumn{3}{c}{ Diagonais $(3 \times 6,1)$} \\
\hline Esforço & Nrd $(\mathrm{kN})$ & Nsd $(\mathrm{kN})$ & $\%$ & Nrd $(\mathrm{kN})$ & Nsd $(\mathrm{kN})$ & $\%$ \\
\hline Compressão & 267,76 & 242,54 & $90,6 \%$ & 146,21 & 70,57 & $48,3 \%$ \\
\hline Tração & 533,18 & 301,06 & $56,5 \%$ & 244,95 & 102,78 & $42,0 \%$ \\
\hline
\end{tabular}

Fonte: autor.

Tabela 8 - Verificações das barras das treliças das vigas

\begin{tabular}{c|c|c|c|c|c|c|c|c|c}
\hline Barra & \multicolumn{3}{|c|}{ Banzos (7x14,6) } & \multicolumn{3}{c|}{ Diagonais (6x12,2) } & \multicolumn{3}{c}{ Montantes (6x12,2) } \\
\hline Esforço & $\begin{array}{c}\text { Nrd } \\
(\mathrm{kN})\end{array}$ & $\begin{array}{c}\text { Nsd } \\
(\mathrm{kN})\end{array}$ & $\%$ & $\begin{array}{c}\text { Nrd } \\
(\mathrm{kN})\end{array}$ & $\begin{array}{c}\text { Nsd } \\
(\mathrm{kN})\end{array}$ & $\%$ & $\begin{array}{c}\text { Nrd } \\
(\mathrm{kN})\end{array}$ & $\begin{array}{c}\text { Nsd } \\
(\mathrm{kN})\end{array}$ & $\%$ \\
\hline Compressão & 327,55 & 135,37 & $41,3 \%$ & 116,41 & 116,02 & $99,7 \%$ & 199,33 & 104,28 & $52,3 \%$ \\
\hline Tração & 580,22 & 137,41 & $23,7 \%$ & 486,14 & 141,51 & $29,1 \%$ & 486,14 & 90,75 & $18,7 \%$ \\
\hline
\end{tabular}

Fonte: autor.

\section{RESULTADOS E DISCUSSÃO}

Resumidamente, os perfis que atenderam a todos os requisitos para o caso do pórtico composto por perfis de alma cheia foram: W 250x89,0 (H) para o pilar; W 460×52,0 para a viga. Em se tratando do pórtico treliçado, os perfis U que atenderam aos esforços de compressão e tração e aos requisitos de montagem foram: 

a) banzos do pilar $5 \times 13,4$;
b) diagonais do pilar, $3 \times 6,1$;
c) banzos da viga, $7 \times 14,6$;
d) diagonais e montantes da viga, $6 \times 12,2$.

Para os galpões estarem de acordo com as verificações da NBR 8800 (ABNT, 2008), houve a necessidade de alterar os perfis estimados no prédimensionamento, item 3.2. O peso do pórtico em perfis de alma cheia calculado foi de $1,29 \mathrm{kN} / \mathrm{m}$ e o peso dos perfis treliçados $0,72 \mathrm{kN} / \mathrm{m}$. A diferença acrescida com os novos perfis, comparado com a estrutura estimada foi a seguinte: alma cheia, $28,38 \%$; treliça, $34,25 \%$. Entretanto, essa diferença na carga permanente ficou em apenas, $11,41 \%$ e $9,00 \%$, respectivamente, considerando que no montante das cargas permanentes, essa diferença é pequena, os esforços solicitantes não foram revistos. Além disso, todos os perfis tiveram resistência superior à solicitação, o que também justifica não ser necessário rever as solicitações.

Avaliando a representatividade do peso da estrutura em relação aos demais pesos que compõem a carga permanente, tem-se uma distribuição apresentada pelos gráficos da Figura 7. Percebe-se, que no pórtico treliçado, a estrutura tem menor representatividade no total de cargas permanentes, se comparado com os perfis de alma cheia, o que justifica o erro percentual na estimativa do peso da estrutura ser menor no montante final.

Figura 7 - Representação das cargas permanentes nas estruturas

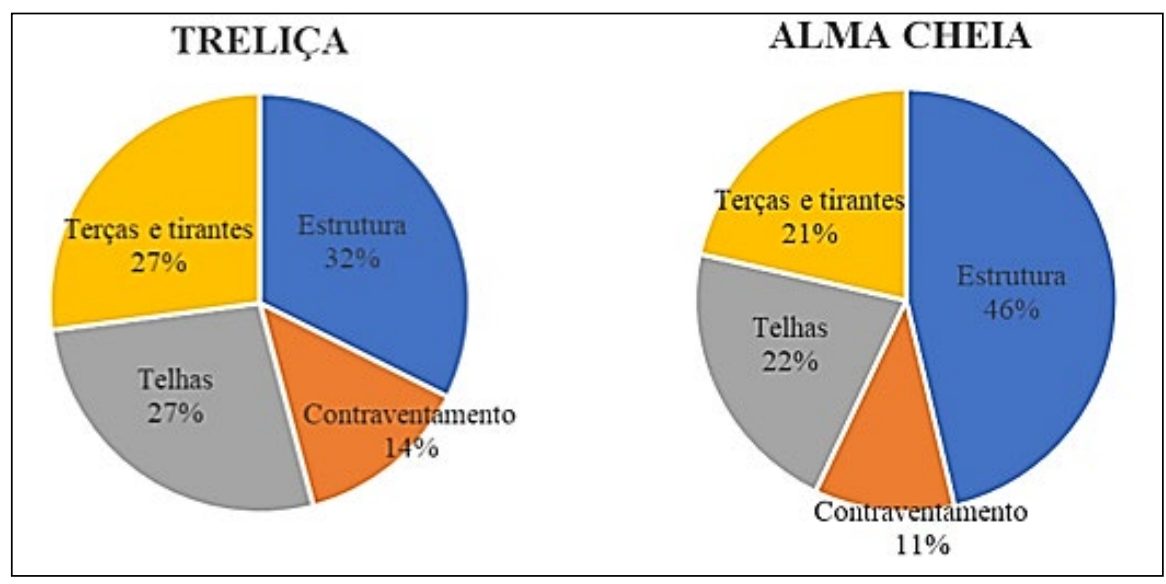

Fonte: autor.

O galpão em alma cheia ficou com $26,00 \%$ a mais de aço, comparando com a estrutura treliçada. Essa diferença percentual equivale a $0,57 \mathrm{kN} / \mathrm{m}$, que é a diferença do pórtico em alma cheia $(2,79 \mathrm{kN} / \mathrm{m})$ comparado ao pórtico 
treliçado $(2,22 \mathrm{kN} / \mathrm{m})$. A Figura 8 ilustra essa diferença onde tem-se o peso do pórtico e o peso total (todas cargas permanentes).

Portanto, o galpão que utilizará menor quantidade de aço é o treliçado, logo, seria o mais econômico avaliando somente os materiais para estrutura, pois em se tratando de estruturas metálicas, este é um parâmetro diretamente relacionado ao custo. Entretanto, vale enaltecer que a montagem das treliças é trabalhosa e requer mais horas de mão de obra devido ao maior número de ligações se comparado com o pórtico de alma cheia. Desta maneira, seria interessante realizar estudo complementar considerando o custo total da obra, o que provavelmente deixaria o sistema treliçado com valor mais alto para o vão escolhido neste trabalho.

Figura 8 - Comparativo de peso $(\mathrm{kN} / \mathrm{m})$

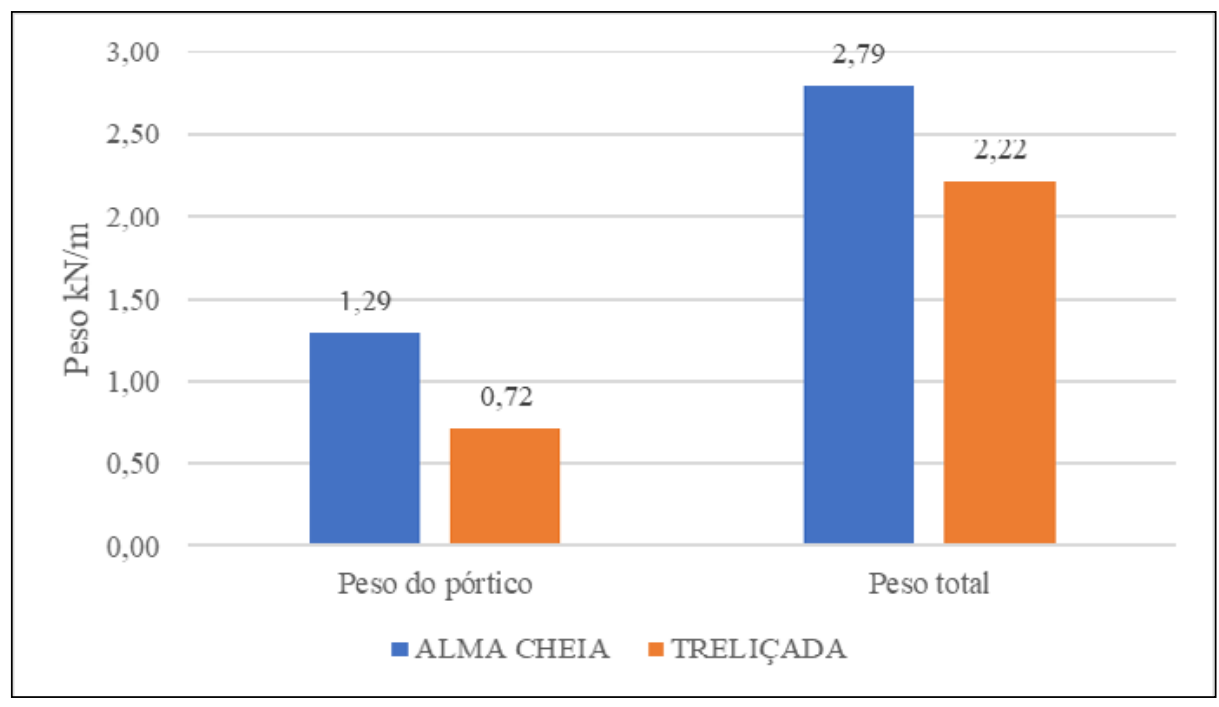

Fonte: autor.

No intuito de comparar os resultados obtidos com outros trabalhos, avaliou-se os trabalhos de Madeira (2009) e Nogueira (2009). Madeira (2009) comparou dois pórticos metálicos, um em alma cheia e o outro composto por treliças e chegou a uma taxa de consumo de aço de $21,00 \%$ maior para o pórtico em alma cheia. Segundo o referido autor, a diferença pode variar conforme a geometria da treliça.

Nogueira (2009) conclui que os pórticos em alma cheia conseguem competir com os pórticos treliçados quanto à taxa de consumo de aço nos vãos de 20, 24 e $28 \mathrm{~m}$, apesar do sistema em treliças ainda ser mais econômico. O referido autor considerou bases rotuladas e engastadas, sendo que o sistema rotulado para perfis I foi o que mais se aproximou ao sistema treliçado para o vão de $20 \mathrm{~m}$. Segundo ele, quanto maior for o vão, mais viável é o sistema 
de treliça, devido sua leveza. No presente estudo chegou-se a uma taxa de $26,00 \%$ a mais no consumo de aço para o pórtico composto por perfis de alma cheia com apoio rotulados e isso corrobora o que foi obtido pelos autores acima mencionados.

\section{CONCLUSÃO}

O presente trabalho teve como objetivo comparar o peso do pórtico principal para um galpão hipotético considerando o uso de perfis de alma cheia e o sistema treliçado. Ambos os galpões analisados, um em estrutura de alma cheia e o outro composto por treliças do tipo Pratt nos pilares e Warren nas vigas, foram dimensionados de acordo com a NBR 8800 (ABNT, 2008).

Ao final, foi obtido o peso de $2,79 \mathrm{kN} / \mathrm{m}$ para o pórtico em perfis de alma cheia e 2,22 kN/m para o pórtico treliçado. A diferença de $0,57 \mathrm{kN} / \mathrm{m}$ representa uma diferença percentual de $26,00 \%$ em relação ao pórtico treliçado. Comparado com trabalhos anteriores, percebe-se que o resultado obtido está dentro do esperado, uma vez que Madeira (2009) obteve uma diferença de $21 \%$.

Entende-se que essa diferença é relevante e impacta diretamente no custo de materiais para a estrutura do pavilhão, uma vez que o pórtico principal se repete 10 vezes no galpão analisado. Dessa forma, em um primeiro momento poderia se entender que o galpão com pórticos em perfis de alma cheia terá custo muito superior. Entretanto, cabe salientar que a montagem das treliças é mais trabalhosa devido às ligações e isso também impactará nos custos da edificação. Sendo assim, não se pode afirmar que a opção por perfis I será necessariamente menos econômica.

\section{REFERÊNCIAS}

ASSOCIAÇÃO BRASILEIRA DE NORMAS TÉCNICAS (ABNT). NBR 6123: Forças devidas ao vento em edificações. Rio de Janeiro, 1988.

2004.

NBR 8681: Ações e segurança nas estruturas -Procedimento. Rio de Janeiro,

. NBR 8800: Projeto de estruturas de aço e de estruturas mistas de aço e concreto de edifícios. Rio de Janeiro, 2008.

BAREIRO, W. G. Estudo e Modelagem de Estruturas Treliçadas utilizadas em Galpões Industriais Considerando Imperfeições Iniciais e Efeitos de Segunda Ordem. 2015. 178f. Dissertação (Mestrado em Engenharia Civil) - Pontifícia Universidade Católica do Rio de Janeiro, Rio de Janeiro, 26 fev. 2015. Disponível em: $<$ https://www.maxwell.vrac.puc-rio.br/>. Acessado: em 24 maio. 2019.

BELLEI, I. H. Edifícios industriais em aço: projeto e cálculo. $6^{a}$ edição. São Paulo: Pini, 2010. 
CHAVES, M. R. Avaliação do desempenho de soluções estruturais para galpões leves. 2007. 125f. Dissertação (Mestrado em Engenharia Civil) - Universidade Federal de Ouro Preto. Escola de Minas, Ouro Preto, 12 mar. 2007. Disponível em: <https:/ / www.repositorio.ufop.br/>. Acessado em:25 abr. 2019.

FAKURY, R. H.; SILVA, A. L. R.; CALDAS, R. B. Dimensionamento básico de elementos estruturais de aço e mistos de aço e concreto. São Paulo: Person Education do Brasil, 2016.

GERDAU. Tabela de bitolas. 2018. Disponível em: <https:/ / www2.gerdau.com.br / produtos/perfil-estrutural-gerdau>. Acessado em 21 ago. 2019.

MADEIRA, A. R. Estrutura em aço para galpão industrial: comparação entre soluções com elementos treliçados e de alma cheia. 2009. 73f. Trabalho de diplomação (Graduação em Engenharia Civil) - Departamento de Engenharia Civil. Universidade Federal do Rio Grande do Sul, Porto Alegre, dez. 2009. Disponível em: <https:/ / www.lume.ufrgs.br/handle/10183/24079>. Acessado em: 06 nov. 2019.

MELO, P. R. Pré-dimensionamento de estruturas de madeira, de aço e de concreto para auxílio à concepção de projetos arquitetônicos. 2013. 113f. Dissertação (Mestrado em Engenharia Civil) - Universidade Federal de Uberlândia. Uberlândia, 01 abr. 2013. Disponível em:<http://repositorio.ufu.br/>. Acessado em: 12 set. 2019.

NOGUEIRA, G. S. Avaliação de soluções estruturais para galpões compostos por perfis de aço formado a frio. 2009. 161f. Dissertação (Mestrado em Engenharia Civil) - Universidade Federal de Ouro Preto. Escola de Minas. Ouro Preto, 17 set. 2009. Disponível em: <https://www.repositorio.ufop.br/>. Acessado em: 27 abr. 2019.

PFEIL, W.; PFEIL, M. Estruturas de aço: dimensionamento prático de acordo com a NBR 8800:2008. $8^{a}$ edição. Rio de Janeiro: LTC, 2016.

PRAVIA, Z. M. C. Planilha eletrônica: Perfil U laminado. [S. 1.] 2008.

PRAVIA, Z. M. C.; DREHMER, G. A.; MESACASA JÚNIOR, E. Galpões para usos gerais. $4^{\mathrm{a}}$ edição. Rio de Janeiro: IBS/CBCA, 2010. 